\title{
Acquisition of English Articles by Croatian Primary School Students in Early English Foreign Language Learning
}

\author{
Katica Balenovic ${ }^{*}$ \\ Department of Teacher Studies in Gospic, Gospic University of Zadar, Croatia \\ *Corresponding author: balenovick@net.hr
}

Received May 12, 2014; Revised June 05, 2014; Accepted June 16, 2014

\begin{abstract}
This paper deals with an analysis of transcribed recordings of spontaneous classroom interaction in five classes of primary school students in early EFL learning in Croatia. The study was conducted within the framework of a large research project supported by the Croatian Ministry of Science, Education and Sports. The students involved in this study started learning English at the very beginning of their education. The recordings were made during three consecutive years when the students were at the end of grades one, two and three. Although the students' overall language development showed clear progress, the development of the correct use of definite and indefinite articles remained highly variable. Progress was made in the sense that throughout the years the use of both types of article increased, but incorrect usage was still very frequent. The study shows a clear interdependence between lexis and grammar at the very beginning of English foreign language learning.
\end{abstract}

Keywords: English articles, classroom interaction, early EFL learning

Cite This Article: Katica Balenovic, "Acquisition of English Articles by Croatian Primary School Students in Early English Foreign Language Learning.” American Journal of Educational Research, vol. 2, no. 7 (2014): 436-440. doi: 10.12691/education-2-7-1.

\section{Introduction}

L2 learners of English often have difficulty in mastering the proper use of indefinite and definite articles, especially when their L1 lacks articles [1]. Most of the work on the acquisition of English articles has focused on adult students/learners $[2,3,4]$. There has been no previous longitudinal research on the acquisition of English articles by Croatian primary school students, so there is a clear need to examine this process. We wanted to explore the development of the interlanguage [5] of primary school students over a period of three successive years with special focus on the acquisition of English definite and indefinite articles.

\subsection{Background}

In this part, we will briefly discuss the term interlanguage, since at the very beginning of learning any foreign language students in their oral production are likely to use their mother tongue more than the target language. The semantics of definiteness/indefiniteness will also be discussed, and previous studies on articles in L2 acquisition (Ionin, Zergollern-Miletić, Trenkić) will be considered.

\subsection{Interlanguage}

The term interlanguage was first introduced in the study of SLA by Larry Selinker [6] to describe a language between two systems that exists and develops from L1 in an attempt to approach the target language (TL). Since this term describes language with elements of both languages, sometimes it is called a compromise system [7]. The main characteristics of this notion are seen in simplification, variability, dynamism and especially cross-linguistic influence, or language transfer [8] where we mostly deal with positive and negative language transfer. But language transfer can occur not only from L1 to L2 (forward transfer), but also vice versa, i.e. from L2 to L1 (backward or reverse transfer), or even from L2 to L3 (lateral transfer). In this sense of language transfer or crosslinguistic influence, there is also bidirectional transfer [9] i.e. the interaction of two languages known by the learner.

Crucial components of the language acquisition process include input, intake, output and feedback. Input refers to what is available to the learner in the learning process, while intake refers to what is actually "taken in" by the learner. Feedback provides learners with information about their utterances and gives them chances to focus on production or comprehension. In this study, we will mostly deal with the notion of output, which was introduced by Swan [10] as "comprehensible" or "pushed" output in which learners are pushed in their production as a necessary part of the learning process.

\subsection{On Definiteness/Indefiniteness}

The linguistic category of definiteness/indefiniteness is often seen as a linguistic universal $[11,12]$, i.e. a universal 
feature of learners' linguistic knowledge as an absolute universal that exists in every human language. What is different is the way this category is expressed in certain languages, either by linguistic patterns such as articles, or some other elements such as determiners. The lack of articles in the learners' L1 presupposes constraints and difficulties in article choice in L2 acquisition. Since Croatian lacks an article system, it is unlikely that L1 transfer affects the acquisition of English articles by Croatian learners. It remains to examine the role of the Universal Grammar (UG) approach [13] in the acquisition of this category as well as the role of the Fluctuation Hypothesis [14] in the acquisition of English articles.

In standard English grammars, articles [15] are found with other determiners as a closed system to express definiteness/indefiniteness, where the definite article indicates that the referent is already shared between the speaker and hearer [16] or they share knowledge of the same. When the situation of this is visible, demonstrative pronouns can be used instead of the definite article, which is explained by Hawkins' location theory [17]. The definite article sometimes expresses the uniqueness [18, 19] of a referent where demonstrative pronouns cannot be used instead of an article. The indefinite article $a$ marks or signals that new information, mentioned for the first time, is introduced in a discourse set. Sometimes indefinite pronouns (any, some) can be used in such situations, or even the number one instead of an indefinite article. This often happens when the learners' L1 lacks an article system (for example, in the present study). If there is no shared knowledge [20] between the speaker and hearer, or a shared previous discourse set [21], the definite article is used. Thus, article choices depend on the notion of definiteness that Ionin [22] describes as a discourserelated semantic feature related to the knowledge state of the speaker and hearer, while the notion of specificity refers to the knowledge known only to the speaker (writer). For example: I want to talk to the owner of this store, whoever that is; I want to talk to the owner of this store, she is my neighbour. The second example implies that information is known and important only to the speaker. Definiteness and specificity are notions important for the Article Choice Parameter [23], by which the author explains the variability in the L2 learners' production of articles that leads to the Fluctuation Hypothesis. Under this hypothesis, L2 learners are predicted to fluctuate between the two settings of the Article Choice Parameter until the input leads them to the right option.

\subsection{Previous Research of Articles in $\mathbf{L} 2$ Acquisition}

The research results of Ionin et al. [24] show that fluctuation overrides language transfer with article-less L1 learners (Russian), while transfer overrides fluctuation with article L1 learners (Spanish) where they transfer the article semantics from their L1 to their L2. In our study, we assume that fluctuation will override transfer since Croatian lacks an article system. Zergollern-Miletić conducted a study on native speakers of Croatian/advanced L2 speakers of English for the purpose of examining their perception of definiteness/indefiniteness in English and Croatian. The research results show the wrong use of articles with abstract nouns and the omission of articles when the noun is defined by an adjective, as well as article substitution (definite for indefinite and vice versa). The author concluded that learners have to develop awareness of the existence of definiteness/indefiniteness in their first language, despite the lack of articles. In Trenkić [25], L2 learners (Serbian) were found to supply the definite article in the place of the indefinite article more often with concrete noun phrases referring to concepts with a relatively constant form (e.g. a letter) than with abstract noun phrases referring to concepts which can take many different forms (e.g. a disaster). Trenkic [26,27] questions the notion of definiteness and asks why the majority of the world's languages can do without the formal marking of this concept through articles. The author considers this term as identification of the referent in a discourse. A discourse referent is definite if the speaker intends to refer to it, and expects the referent to be uniquely identifiable to the hearer (e.g. Pass me the black mug please). When existence and uniqueness are not met, the referent is indefinite (e.g. Pass me a white mug please). In Ionin, Ko, and Wexler's [28] study, L2 learners inappropriately used the definite article in indefinite contexts such as a girl from my class where the referent is identified by the speaker, rather than when the speaker denies knowledge of the referent. Ogawa [29] conducted a study on articleless L1 learners (Japanese) based on the idea that the difficulty of article acquisition lies in nominal countability as well as in definiteness and specificity [30]. It was discovered that advanced EFL learners had difficulty in recognizing nominal countability. What was unsolved in this study and what the author considered important in the proper use of articles was what kind of context determines the countability of abstract nouns, i.e. if those nouns are the "carrier" or "shell" (e.g. fear, or the fear of contracting AIDS). The context determines the article as well as the form of a noun (an abstract noun becomes countable).

\section{Research - Aim and Methodology}

\subsection{Aim of the Study}

The aim of our research was to analyse the process of article acquisition of primary school EFL learners, with the goal of disentangling the factors which might influence that process. The study was conducted longitudinally within the framework of a large research project (Early acquisition of English as a foreign language: the analysis of learner's interlanguage) supported by the Croatian Ministry of Science, Education and Sports. Our initial hypotheses in this research are:

$\mathrm{H} 1$ - the use of the indefinite article $(a, a n)$ is more frequent than the use of the definite article (the) for early EFL learners.

$\mathrm{H} 2$ - the correct use of the L2 article system gradually increases over the years of learning.

H3 - there is a clear interdependence between lexis and grammar at the beginning of EFL learning.

\subsubsection{Participants}

A total of 93 Croatian EFL learners from five primary schools (classes) from different counties were observed over a period of three years. The recordings of 
spontaneous classroom interaction were taken at the end of the first, second and third grade.

\subsubsection{Methods}

The students were informed and prepared for the recordings by previous observation of classroom interaction. They were also informed about the aim and the purpose of the study, and it was made clear to them that their participation in the study was voluntary and anonymous, and that the information would be used for scientific purposes only. The recordings included students' oral production in spontaneous classroom interaction, lasting for one school hour, and were made at the end of the first, second and third grades (a total of 15 recordings). After the recordings were made, they were prepared for further analysis by using CHAT (Codes for Human Analysis of Transcripts), as a part of CHILDES (Child Language Data Exchange System) [31,32] made for the analysis of children's oral production. CHAT is a transcription and coding system, which is formatted to be compatible with the analysis tools. The conventions and notation system are described in detail in the CHAT manual (http.//childes.psy.cmu.edu/manuals/CHAT.pdt). Here we will only outline the most important features of this transcription which are necessary to fully understand the further analysis. The most important feature of CHAT, from the point of view of the analysis, is the organisation of the transcripts in a number of tiers, called the main tier and a range of dependent tiers. The main tier is the line on which what the speakers have actually said is transcribed; it always starts with an asterisk followed by a three letter code representing the speaker, e.g. *B01. In our study we included all the students (speakers) in the class. Dependent tiers (lines) are where tags or comments are inserted (either manually or automatically, depending on the tier), and always start with a \% sign. We excluded these tiers from further analysis, since the focus in this research was on the students' utterances (see more in the following part). After finishing the transcription of the collected oral data production, the transcripts were ready for analysis by using CLAN (Computerised Language Analysis) tools, also as a part of CHILDES (for details see MacWhinney, [33]). CLAN is a suite of analysis programs which enable automatic tagging and searching of the transcripts. The use of these tools provide quantitative analysis of the students' oral production in spontaneous classroom interaction, which included the number of morphemes, type/token ratio, mean length of utterance (MLU), as well as the frequency of the use of definite and indefinite articles. For the purpose of this study, an additional program COMBO (searches for complex string patterns, i.e. in our study, articles) was also used. Below we present part of a transcribed recording using COMBO, searching for a particular string (in this case the definite article the) in classroom interaction:

From file $<$ c: $\backslash$ childes\Optimus \bilje3.09.cha $>$

*** File "c:\childes\Optimus \bilje3.09.cha": line 98. *B01: (1) the Lennons are at home.

*** File "c:Ichildes\Optimus\bilje3.09.cha": line 101. *B01: Rosie and grandma are in (1) the living room.

*** File "c:|childes\Optimus \bilje3.09.cha": line 106.
*B21: Bob and Toto are in (1)the kitchen, Bob is eating sausages.

*** File "c:\childes\Optimus\bilje3.09.cha": line 109.

*B02: Mum is in (1) the study.

After doing the quantitative analysis of all three recordings from five classes (schools), we conducted a qualitative analysis of the transcripts. The quantitative analysis was carried out using error analysis, i.e. proper/wrong use or omission of the article.

\section{Research Results}

As mentioned above, the quantitative analysis was performed in CLAN and focused on the gradual development of lexical diversity and syntactic complexity. The results showed an increase in the overall number of morphemes per recording. There was also an increase in the MLU (mean length of utterance) as well as in the type/token ratio. We concluded that throughout the years of learning, communicative language proficiency systematically increases, which was expected since there is a formal exposure of learning over the years. The focus in this study was on the frequency and accuracy of article use in the classroom interaction of primary EFL learners. The analysis of classroom interaction was done among classes (schools) with the aim of showing the frequency of article use at the end of the first, second and third grades. The following is a comparison of the frequency of the use of the indefinite article among the schools over the three years of the EFL learning process:

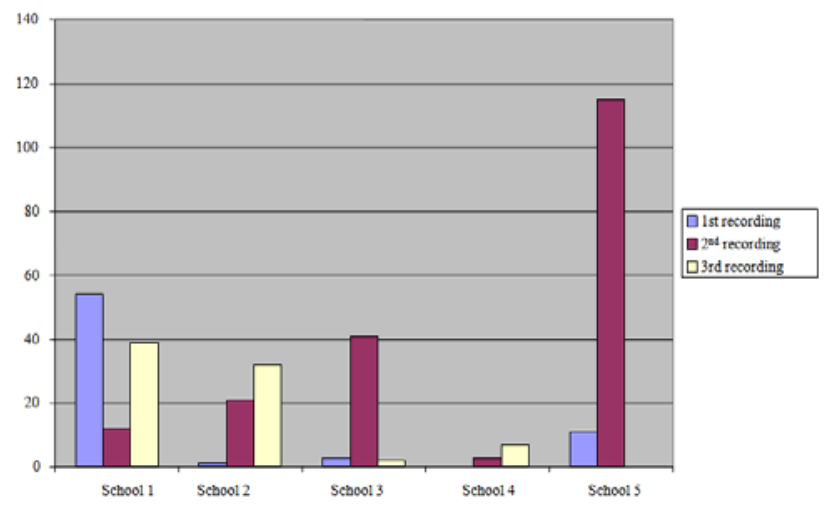

Figure 1. The frequency of indefinite article use in classroom interaction

As seen above, the indefinite article is mostly used in all classes and recordings, except school 4 in the first recording. The result is expected since it is the very beginning of EFL learning. The most frequent indefinite article use is in the fifth school ( $2^{\text {nd }}$ recording). The qualitative analysis showed the reason for such frequency. The pupils often repeated the same utterance (Have you got a pet?). From the above data we conclude that learners use the indefinite article in their utterances although the mean length of utterance is relatively short $(\mathrm{Mv}=2,714)$. But, there is very frequent omission of the indefinite article, especially in front of a word (noun) beginning with a vowel sound (*apple), or if a noun is not familiar to the learners. As pointed out at the beginning of this article, there is a clear interdependence between lexis and 
grammar, especially when learners in their L1 lack an article system (Croatian).

Figure 2 shows the frequency of the use of the definite article among the observed schools (classes) in three recordings:

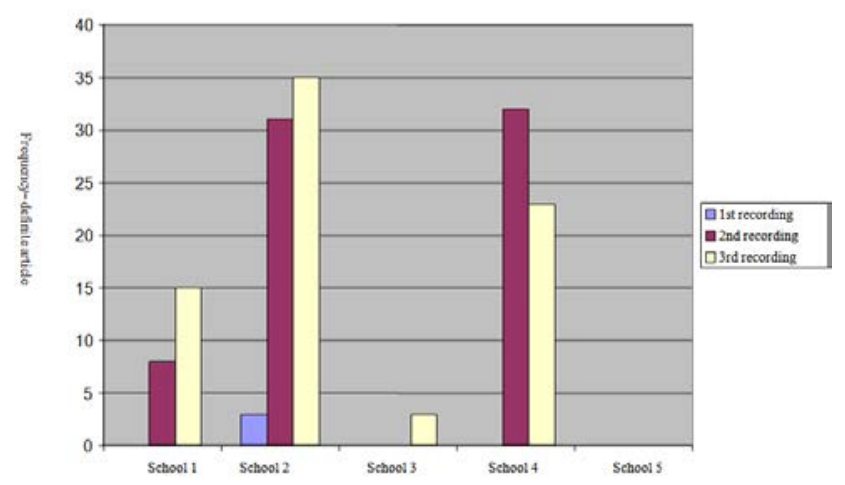

Figure 2. The frequency of definite article use in classroom interaction

As seen above, there are some classes (schools) and recordings (the first recordings in all classes, except for school 2) where the definite article is not used at all. In comparison to the use of the indefinite article, we conclude that learners use the indefinite article more than the definite article in their utterances. This is due to the fact that the pupils in early EFL learning are first introduced to the indefinite article (as the results of this study confirm) and are introduced to the definite article in the later phases of learning. So, the data analysis shows the more frequent proper use of the indefinite than the definite article. This can also be explained by the more frequent exposure to the former in the classroom context. These data confirm our first and second hypotheses.

The qualitative analysis also showed the correct use of the indefinite article in front of familiar nouns. Learners tend to omit the indefinite article in front of unfamiliar nouns. We conclude that there is an interdependence of lexis and grammar especially at the beginning of EFL learning. This confirms our third hypothesis. There is also omission of the 'an' form of indefinite article due to the very few familiar nouns with an opening vowel and which also pose pronunciation difficulty for young learners. The same could be said for the pronunciation of the definite article as well. The qualitative analysis also showed omission of the indefinite article at the beginning of a sentence and the correct use of the definite article in the same sentence (e.g. *pencil is on the box, confirmed also in Trenkić, Jarvis).

\section{Conclusion}

The findings demonstrate the problem that Croatian learners of English have in mastering English articles. The analysis revealed that frequent exposure to both types of articles and frequent repetition of structures including them increase the correct use of both definite and indefinite articles. However, inconsistency in the use of both types of articles indicates a long and fluctuating process of acquisition. The analysis also revealed the tendency to omit articles, especially at the beginning stages of learning, probably due to the non-existence of articles in the participants' L1 (Croatian). We finally conclude that there is a need to develop learners' awareness of the existence of the article in English and its semantic and pragmatic role. The study provides support for the Fluctuation Hypothesis, i.e. students who lack articles in their L1 fluctuate between the use of the definite and indefinite article over an extended time period.

\section{References}

[1] Lightbown, P. \& Spada, N. How Languages are Learned, 3rd ed. OUP, Oxford, 2006.

[2] Trenkić, D. Form-meaning conections int he acquisition of English articles, Second Language research, vol. 23, No. 3, 289327, 2002.

[3] Trenkić, D. Definiteness in Serbian/ Croatian/ Bosnian and some implications for the general structure of nominal phrase, Lingua 114, 1401-1427, 2002.

[4] Zergollern-Miletić,L Kategorija određenosti $i$ neodređenosti u engleskom i hrvatskom jeziku, Unpublished doctoral theses, Filozofski fakultet, Zagreb, 2008.

[5] Selinker,L. Interlanguage, International Review of Applied Linguistics, 10, 209-231, 1972.

[6] Selinker, L. Rediscovering Interlanguage (Applied Linguistics and Language Study), Longman, London, 1992.

[7] Filipović, R. A compromise System, B.Studies, Institute of Linguistics, Zagreb. 19-29, 1972.

[8] Jarvis,S. \& Pavlenko,A. Crosslinguistic Influence in Language and Cognition, Routledge, New York, 2007.

[9] Medved Krajnović, M. Od jednojezičnosti do višejezičnosti, Uvod u istraživanja procesa ovladavanja inim jezikom, Leykam international, d.o.o., Zagreb, 2010.

[10] Swain, M. Communicative competence: some roles of comprehensible input and comprehensible output in its development. In Gass, C.G. (ed), Input in SLA. Rowley, MA:Newbury House, 1985.

[11] Chomsky, N. On Nature and Language, ed. A. Belletti \& L. Rizzi. CUP, Cambridge, 2002.

[12] Silić.J.Ktegorija neodređenosti/određenosti i načini njezina izražavanja, Riječki filološki dani, 401-405., 2000.

[13] Chomsky, N. New Horizons in the Study of Language and Mind, CUP, Cambridge, 2000.

[14] Ionin, T. Acquisition of article semantics by child and adult L2English learners, Bilingualism: Language and Cognition, 12, 337361, 2009.

[15] Eastwood, J. Oxford Learner's Grammar, Grammar Finder, OUP, Oxford, 2005.

[16] Robertson, D. Variability in the use of the English article system by Chinese learners of English, Second Language Research, 16, 135-172.2000.

[17] Hawkins, J.A. Definiteness and Indefinitenes, Croom Helm, London. 1978.

[18] Hawkins, J.A. On (in) definite articles: implicatures and (un) grammaticality predictions, Journal of Linguistics, 27, 405-442, 1991.

[19] Heim, I. Articles and definiteness, Semantics: An international handbook of contemporary research, de Gruyter, Berlin, 1991.

[20] Yule, G. Explaining English Grammar, OUP, Oxford, 1998.

[21] Hawkins, J.A. Efficiency and Complexity in Grammars, OUP, Oxford, 2004.

[22] Ionin, T. Article Semantics in Second Language Acquisition, Doctoral dissertation, MIT, Cambridge, Mass, 2004.

[23] Ionin, T. This is definitely specific: specificity and definiteness in article systems, Natural Language semantics, 14, 175-234, 2007.

[24] Ionin, T., Ko, H., \& Wexler K. Article semantics in L2 acquisition: the role of specificity, Language Acquisition, 12, 3-69, 2006.

[25] Trenkić, D. Definiteness in Serbian/Croatian/Bosnian and some implications for the general structure of nominal phrase, Lingua 114, 1401-1427, 2004.

[26] Trenkić, D. Variability in second language article production: beyond the representational deficit vs. Processing constraints debate, Second Language Research 23 (3), 289-327, 2007.

[27] Trenkić, D. Accounting for patterns of article omission and substitutions in second language production, in R. Hawkins \& M.P.G. Mayo (eds.) Second language acquisition of articles: 
Empirical findings and theoretical implication, John Benjamins, Amsterdam, 115-143, 2009.

[28] Ko, H., Ionin, T. \& Wexler, K. L2-Acquisition of English Articles by Korean Speakers, Handbook of East Asian Psycholinguistics: Korean, CUP, Cambridge, 1-31, 2006.

[29] Ogawa, M. The Acquisition of English Articles by Advanced EFL Japanese Learners: Analysis Based on Noun Types, Journal of Language Culture Language and Information, Vol. 3, Department of Language and Culture School of Humanities and Social Sciences, Osaka prefecture University, Osaka. 133-151.2008.
[30] Hawkins, R. Accounting for English article interpretation by L2 speakers, in S. Forster-Cohen, M. Amsterdam, 7-25, 2006.

[31] Mac Whinney, B. The CHILDES Project: Tools for Analyzing Talk, 2nd ed. Mahwah, NJ: Lawrence Erlbaum and Associates. http://childes.psy.cmu.edu/

[32] MacWhinney, B. The CHILDES Project: Tools for Analyzing Talk, The CHAT Transcription Format, 3nd ed. Mahwah, NJ: Lawrence Erlbaum and Associates. http://childes.psy.cmu.edu/,.

[33] Mac Whinney, B. The CHILDES Project: Tools for Analyzing Talk, CLAN Manual, 3nd ed. Mahwah, NJ: Lawrence Erlbaum and Associates, 2010. 